Rechtsmedizin 2021 · 31:395-404

https://doi.org/10.1007/s00194-021-00508-2

Angenommen: 11. Mai 2021

Online publiziert: 26 . Juli 2021

(c) Der/die Autor(en) 2021, korrigierte Publikation 2022

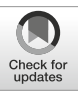

\section{Möglichkeiten und Grenzen der forensischen DNA-Analyse unter dem Gesichtspunkt verschiedener Szenarien zur Spurenentstehung}

\author{
Eine Stellungnahme der gemeinsamen Spurenkommission \\ der rechtsmedizinischen und kriminaltechnischen Institute
}

\author{
Marielle Vennemann ${ }^{1} \cdot$ Claus Oppelt $^{2} \cdot$ Stefanie Grethe ${ }^{3} \cdot$ Katja Anslinger $^{4}$. \\ Rolf Fimmers ${ }^{5} \cdot$ Harald Schneider ${ }^{6}$. Carsten Hohoff $\cdot$ Martin Eckert ${ }^{8}$. \\ Thomas Rothämel $^{9}$ · Peter M. Schneider ${ }^{10}$ - als Mitglieder der Spurenkommission, der \\ gemeinsamen Kommission rechtsmedizinischer und kriminaltechnischer Institute \\ ${ }^{1}$ Institut für Rechtsmedizin, Westfälische Wilhelms-Universität Münster, Münster, Deutschland \\ ${ }^{2}$ Landeskriminalamt Niedersachsen, Hannover, Deutschland \\ ${ }^{3}$ Landeskriminalamt Rheinland-Pfalz, Mainz, Deutschland \\ ${ }^{4}$ Institut für Rechtsmedizin, Ludwig-Maximilians-Universität, München, Deutschland \\ ${ }^{5}$ Institut für Forensische Statistik und Qualitätssicherung GbR, St. Augustin, Deutschland \\ ${ }^{6}$ Hessisches Landeskriminalamt, Wiesbaden, Deutschland \\ ${ }^{7}$ Institut für Forensische Genetik, Münster, Deutschland \\ ${ }^{8}$ Bundeskriminalamt, Wiesbaden, Deutschland \\ ${ }^{9}$ Institut für Rechtsmedizin, Medizinische Hochschule Hannover, Hannover, Deutschland \\ ${ }^{10}$ Institut für Rechtsmedizin, Medizinische Fakultät und Universitätsklinik, Universität zu Köln, Köln, \\ Deutschland
}

Die Spurenkommission ist eine Arbeitsgemeinschaft der Deutschen Gesellschaft für Rechtsmedizin (DGRM); s. https://www.dgrm. de/arbeitsgemeinschaften

Die Autoren M. Vennemann, C. Oppelt, S.Grethe und K. Anslinger sind gleichberechtigte Erstautoren.

Aus Gründen der besseren Lesbarkeit wird auf die gleichzeitige Verwendung der Sprachformen männlich, weiblich und divers $(\mathrm{m} / \mathrm{w} / \mathrm{d})$ verzichtet. Sämtliche Personenbezeichnungen gelten gleichermaßen für alle Geschlechter.

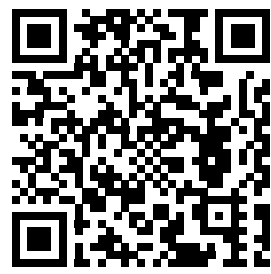

QR-Code scannen \& Beitrag online lesen

\section{Einleitung}

Die DNA-Analyse von Tatortspuren und der Direktvergleich mit DNA-Mustern möglicher Spurenverursacher sind zu unverzichtbaren Werkzeugen der Strafverfolgungsbehörden geworden. Allein mithilfe der beim Bundeskriminalamt angesiedelten DNA-Analyse-Datei (DAD) konnten im Jahr 2019 etwa 19.000 Spuren gespeicherten Personen und über 5000 Spuren weiteren Tatortspuren zugeordnet werden, wodurch mögliche Tatzusammenhänge aufgedeckt werden [1].

Vor allem drei technische Weiterentwicklungen haben die Zuverlässigkeit und Auswertbarkeit forensischer DNA-Analysen enorm verbessert und parallel zur o.g. Entwicklung zu einem deutlich gestiegenen Aufkommen an zu analysierenden DNA-Spuren geführt:
- empfindlichere Methoden, die eine DNA-Typisierung auch bei minimalen Spurenmengen zulassen;

- die Tendenz, immer mehr genetische Merkmalssysteme (Marker) im humanen Genom parallel zu untersuchen und

- die konsequente Anwendung, Standardisierung und Weiterentwicklung etablierter statistischer Verfahren („likelihood ratio“), welche die Berechnung von Wahrscheinlichkeiten für die Beobachtung der DNA-Spuren auf der Grundlage verschiedener, sich gegenseitig ausschließender Hypothesen und damit eine objektive Bewertung, auch bei Vorliegen unvollständiger Teil- oder Mischprofilen, ermöglichen.

Die routinemäßige Analyse einer großen Anzahl von Merkmalssystemen (heu- 
te üblicherweise mindestens 16) hat die Möglichkeit einer Individualzuordnung geschaffen: Bereits ein DNA-Profil, das 12 Merkmalssysteme umfasst, kommt rechnerisch höchstens einmal unter 30 Mrd. Menschen vor. In der Praxis sind weit größere Seltenheitswerte die Regel. Lediglich eineiige Zwillinge lassen sich auf diese Weise nicht unterscheiden, da sie naturgemäß ein identisches DNAProfil besitzen.

Die Möglichkeit, immer geringfügigere DNA-Spuren zu detektieren, und die Feststellung des BGH, dass sowohl das angewandte DNA-Verfahren als auch die biostatistische Bewertung i.d.R. als standardisiert gelten können (BGH 3 StR 46/12; BGH 4 StR 439/13; BGH 5 StR 50/17), führte im Laufe der letzten Jahre zu einer deutlichen Verlagerung der an Sachverständige im Rahmen oder im Vorfeld einer Hauptverhandlung gestellten Fragen. So sollen immer häufiger alternative Szenarien zur Entstehung einer Spur - wie beispielsweise aufgrund eines indirekten DNA-Transfers beurteilt werden.

Aus Sicht der Spurenkommission wird diese Entwicklung grundsätzlich begrüßt, sie sieht allerdings für die Bewertung und Interpretation der DNA-Befunde unter Berücksichtigung verschiedener Szenarien zur Entstehung der Spur Klärungsund Diskussionsbedarf. Denn es besteht die Gefahr, dass je nach Fallkonstellation einerseits die Tatrelevanz einer DNA-Spur, andererseits aber auch die Möglichkeit des indirekten DNA-Transfers als „alternative" Erklärung der Spurenentstehung überbewertet werden.

Die Tatrelevanz einer Spur und ihr möglicher Beitrag zur Aufklärung eines Tatgeschehens sollten bereits vor der DNAUntersuchung kritisch geprüft werden. Erfolgt beifraglich tatrelevanten Spuren dennoch eine molekulargenetische Analyse, müssen allen Ermittlungs- und späteren Verfahrensbeteiligten die Grenzen der Aussagekraft dieser DNA-Spur bewusst sein.

Im Gegensatz dazu besteht die Gefahr der Überinterpretation des DNA-Sachbeweises in besonderem Maße, wenn die häufig mit biostatistischen Methoden erreichten hohen Evidenzen für die Spurbeteiligung einer oder mehrere Personen unreflektiert auf die Beantwortung anderer Fragen übertragen werden, wie z.B.

Die forensische DNA-Analyse hat sich in den letzten Jahrzehnten mit zunehmender Sensitivität und gleichzeitiger Standardisierung der Methodik zu einem festen Bestandteilteil der Strafverfolgung entwickelt. Dank der ständigen Verbesserung der Analysemethoden ist es zwischenzeitlich nahezu selbstverständlich, immer kleinere, latente DNA-Spuren erfolgreich zu typisieren. Dies führt mehr und mehr zu einer Verlagerung der Sachverständigentätigkeit in die Bewertung komplexer Spurenszenarien im Rahmen einer Hauptverhandlung: Anstelle der Zuordnung einer Spur zu einer Person rückt die Spurenentstehung bzw. die Möglichkeit eines DNATransfers ohne Bezug zu einer strafrechtlich relevanten Handlung in den Fokus der Diskussion. Aus Sicht der Deutschen Spurenkommission erscheint es notwendig, das Bewusstsein für mögliche alternative Szenarien zur Spurenentstehung zu schärfen. Zur Einordnung eines DNA-Ergebnisses in den Kontext der übrigen Sachbeweise eines konkreten Fallszenarios wird im vorliegenden Beitrag das bereits in der internationalen Fachliteratur seit geraumer Zeit etablierte Konzept der "Hierarchie der Hypothesen“ vorgestellt. Darüber hinaus werden die wissenschaftlichen Grundlagen zur Bewertung alternativer Szenarien des DNA-Transfers erläutert und gleichzeitig die Möglichkeiten und Grenzen einer gutachterlichen Stellungnahme dargestellt.

\section{Schlüsselwörter}

„Hierarchy of propositions" · DNA-Transfer · Wahrscheinlichkeit · Sachverständigengutachten · Forensische Genetik

der Frage nach der Entstehung einer Spur. Das üblicherweise von DNA-Sachverständigen mitgeteilte biostatistische Ergebnis bezieht sich ausschließlich auf die Erklärung einer Spur durch das DNA-Profil einer Person. Diese Bewertung auf Identitätsebene - Wer hat die DNA-Spur hinterlassen?-ist jedoch in keinem Fall übertragbar auf Fragen zum Zeitpunkt der Spurenentstehung oder zu den möglichen Aktivitäten, durch die die untersuchte DNA-Spur an den Ort der Sicherstellung gelangt ist. Besondere Vorsicht ist z. B. in Fällen geboten, in denen sich ein Tatverdacht durch eine einzige, latente Minimalspur und einen Treffer in der DAD ergibt, oder in Fällen, in denen Beschuldigte auch Tatortberechtigte sind.

Es ist daher ein Ziel dieser Arbeit, das Bewusstsein für diese Überlegungen hinsichtlich der Tatrelevanz und möglichen Überbewertungen von DNA-Spuren im Kontext einer alternativen Spurenentstehung zu schärfen.

In der internationalen Fachliteratur existiert bereits seit Langem das gut etablierte Konzept der „Hierarchie der Hypothesen", wonach die verschiedenen Ebenen, auf welchen das Ergebnis der DNA-Analyse einer Spur betrachtet werden kann, klar voneinander abgegrenzt werden [2-4]. Dies stellt aus Sicht der Spurenkommission ein geeignetes Werkzeug dar, um den Stellenwert der
Ergebnisse einer DNA-Analyse, auch unter Einbeziehung unterschiedlicher Szenarien zur Spurenentstehung, im Kontext der übrigen Sachbeweise einzuordnen. Der vorliegende Artikel führt in die Thematik der Begutachtung der Spurenentstehung auf der sog. Aktivitätsebene ein. Die Autoren schlagen eine Basis vor, auf der fallspezifische Fragen zur Spurenentstehung in Strafverfahren erörtert und ggf. sachverständig beurteilt werden können. Gleichzeitig sollen die Möglichkeiten, aber auch Schwierigkeiten und die damit verbundenen Grenzen einer sachverständigen Stellungnahme zu Szenarien der Spurenentstehung erläutert werden.

\section{Die Hierarchie der Hypothesen}

Die Hierarchie der Hypothesen wurde ursprünglich für alle Bereiche der forensischen Wissenschaften im Sinne eines Rahmenkonzepts zur Spureninterpretation entwickelt $[2,3]$. Dem zugrunde liegt die Betrachtung jeder Spur auf verschiedenen, hierarchisch geordneten Ebenen und somit aus unterschiedlichen Perspektiven. Im Fall der forensischen DNAAnalyse ergeben sich daraus die folgenden Fragestellungen:

- Kann eine eindeutige Übereinstimmung des DNA-Spurenprofils mit einem Vergleichsprofil einer Person festgestellt werden? 


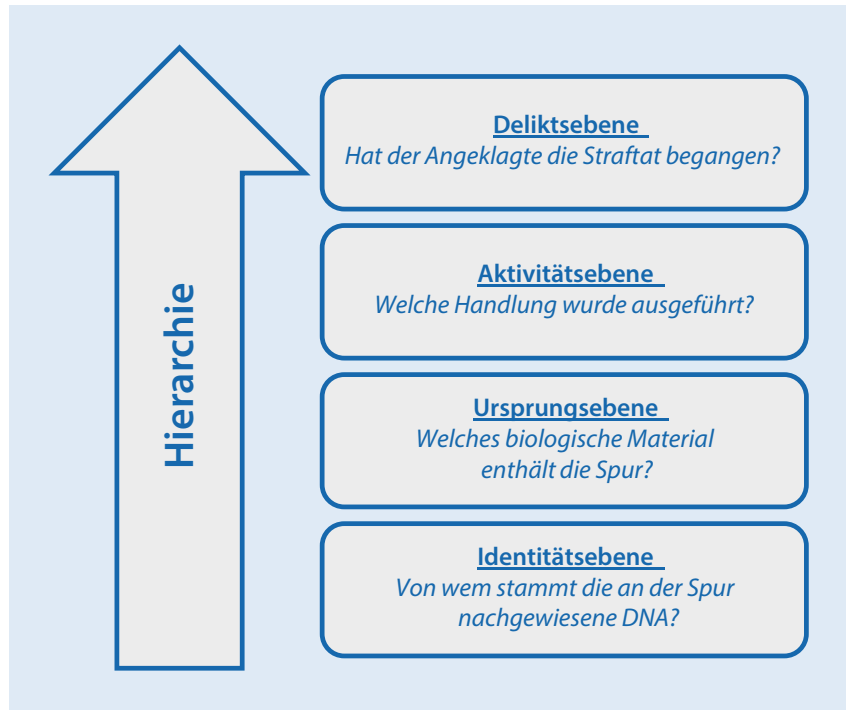

Abb. 1 \ Die Hierarchie der Hypothesen bildet einen gedanklichen Rahmen für die Bewertung von Spuren und deren Analyseergebnissen im Strafverfahren. Die Fragen der einzelnen Hierarchieebenen müssen getrennt voneinander betrachtet werden. Für eine Abklärung des möglichen Antwortspektrums können verschiedene (auch spekulative) Erklärungen angeführt werden. Für eine konkrete Bewertung müssen die Fragen der einzelnen Ebenen zunächst in Hypothesenpaare umgewandelt werden, und es muss eine entsprechende Datenbasis vorhanden sein. (Gill et al. [9])

- Kann die Spur einem biologischen Ursprungsmaterial (z. B. einer Körperflüssigkeit) zugeordnet werden?

- Kann die unterstellte Handlung die Entstehung der Spur erklären?

- Können die DNA-Befunde letztendlich als Sachbeweis für die Feststellung von Schuld/Unschuld gewertet werden?

Die Betrachtung der verschiedenen Hierarchieebenen ist mit einer einfachen Plausibilitätsprüfung jedoch nicht erschöpfend behandelt. Vielmehr bedarf es auf jeder Ebene der Betrachtung möglicher alternativer Erklärungen, aus denen sich konkrete Hypothesen und Gegenhypothesen für die sachverständige Beurteilung ergeben können. Ausgehend von den ursprünglich beschriebenen drei Ebenen der Hypothesenbetrachtung $[2,3]$ werden in der forensischen Genetik vier Ebenen unterschieden ([4, 5]; • Abb. 1).

\subsection{Die Identitätsebene (engl. „sub-source level“)}

\section{Von wem stammt die an der Spur} nachgewiesene DNA?

Auf der Identitätsebene werden Spuren ausschließlich auf der Grundlage der beobachteten DNA-Profile von Spuren- und Vergleichsmaterial betrachtet: Die DNA-Pro-
- H1: „Die in der Spur nachgewiesenen DNA-Merkmale stammen von Person $X^{\prime \prime}$.

- H2: „Die in der Spur nachgewiesenen DNA-Merkmale stammen von einer unbekannten und mit $\mathrm{X}$ nicht verwandten Person".

Die biostatistische Bewertung von DNASpuren auf der Identitätsebene beruht ausschließlich auf den für den jeweiligen Fall angemessenen populationsgenetischen Referenzdaten [6] und ist an anderer Stelle bereits ausführlich beschrieben [7]. Gemäß der geltenden Rechtsprechung des BGH ist dieses Verfahren derart standardisiert (BGH 5 StR 50/17), dass es an dieser Stelle keiner weiteren Erläuterung bedarf.

\subsection{Die Ursprungsebene (engl. „source level“)}

\section{Welches biologische Material enthält die Spur?}

Auf der Ursprungsebene wird in der forensischen DNA-Analytik der Nachweis bestimmter Gewebe- oder Sekretarten (z. B. Blut, Speichel, Sperma, Vaginalsekret) betrachtet, die als biologischer Ursprung der untersuchten DNA-Spur in Betracht kommen. Der Nachweis einer Spurenart erfolgt nicht direkt über die in der Spur enthaltene DNA, sondern üblicherweise in einer separaten Analyse mittels mikroskopischer Nachweisverfahren, über die Detektion gewebe- bzw. sekretspezifischer Proteine oder über zelltypspezifische Ribonukleinsäuren. Da die Ergebnisse der Spurenartbestimmung und der DNA-Analyse unabhängig voneinander gewonnen werden, lässt sich die Zuordnung einer DNA-Spur zu einer Person (Identitätsebene) nicht unmittelbar auf die Zuordnung des vorgefundenen Sekrets/Gewebes zu dieser Person übertragen: Sofern z.B. aus einer Spur mit positivem Blutnachweis lediglich das DNA-Profil einer einzigen Person resultiert, kann i. d. R. davon ausgegangen werden, dass Blut auch der Ursprung des gefundenen DNA-Profils darstellt. Im Falle einer positiv auf humanes Hämoglobin getesteten Blutspur, deren DNA-Untersuchung z.B. einen Mischspurbefund mit DNA-Anteilen von zwei Personen zeigt, lässt sich hingegen nicht ohne Weiteres entscheiden, ob das Blut hier von beiden 
oder nur von einer Person stammt. Ebenso wenig ist eine Aussage darüber möglich, von welcher der beiden Personen das Blut stammt und aus welchem Sekret/Gewebe die DNA der zweiten Person stammt.

\subsection{Die Aktivitätsebene \\ (engl. „activity level“)}

\section{Welche Handlung wurde ausgeführt?}

Betrachtungen auf der Aktivitätsebene beziehen sich auf konkrete Handlungen, welche die Spurenlage erklären können. Vor allem gilt auch hier, dass der biostatistische Wert der Zuordnung des DNA-Profils zu einer Person nicht auf die Assoziation der Person zu einer möglichen (Tat-)Handlung übertragen werden darf. Vielmehr muss man zwischen der Frage nach der Art der Entstehung einer Spur und der Frage nach der Identität des Spurenverursachers unterscheiden. Im Verlauf eines Strafverfahrens könnten beispielsweise zwei Erklärungen zum Auffinden einer Blutspur, deren DNA-Profil mit dem DNA-Profil der Person $X$ übereinstimmt, angeführt werden: Der Erklärung „Person X schlug die Scheibe ein und erlitt dabei eine blutende Verletzung" könnte die alternative Erklärung „Person $X$ verletzte sich nach der Tat an der bereits zuvor zerbrochenen Scheibe" entgegengesetzt werden. Eine Überführung der vorgebrachten alternativen Szenarien in konkrete Hypothesen für die statistische Beurteilung ist auf dieser Aktivitätsebene deutlich komplexer und teilweise unmöglich, da wissenschaftlich solide und auf das jeweilige Szenario passende Vergleichsdaten in der Literatur häufig nicht vorliegen. Diese für die Beweiswürdigung zunehmend bedeutsame Ebene wollen wir nachfolgend ausführlicher beleuchten.

Auch auf Aktivitätsebene betrachtete Handlungen sind nicht zwingend tatrelevant. Die im Fallbeispiel benannte Person $X$ kann in beiden Fällen als Täter in Betracht kommen. Umgekehrt kann die Entstehung der Blutspur auch ohne konkreten Tatbezug erklärt werden, z. B. wenn der Spurenleger einen legitimen Zugang zum Tatort hatte.

\subsection{Die Deliktsebene} (engl. „offence level")

\section{Hat der Angeklagte die Straftat begangen?}

Das Gericht entscheidet auf der höchsten Hierarchieebene über Schuld oder Unschuld des Angeklagten und verwendet dabei Informationen aus den darunterliegenden Ebenen, sowie aus weiteren, von den DNA-Spuren unabhängigen Indizien und Beweisen. Fragen auf Deliktsebene liegen außerhalb des Zuständigkeitsbereiches forensischer Sachverständiger [4].

\section{Praktische Auswirkungen auf die Bewertung von DNA-Spuren}

Die auf internationaler Ebene tätige DNAKommission der International Society for Forensic Genetics (ISFG) weist Sachverständigen zwei verschiedene Rollen zu [8]: Zu Beginn einer Ermittlung, bei der es um die Sichtung und Priorisierung der Spuren mit Tatbezug und um die Identifizierung möglicher (unbekannter) Tatverdächtiger geht, ist der Sachverständige zunächst explorativ tätig. Erst wenn es konkrete Personen gibt, diez. B. über eine Recherche in der DAD oder durch polizeiliche Ermittlungstätigkeit als potenzielle Spurenleger in den Fokus geraten, kann sich die Sichtweise ändern und die sachverständige Person ggf. von Staatsanwaltschaften oder Gerichten beauftragt werden, evaluativ tätig zu werden, um auf der Grundlage konkreter Hypothesen biostatistische Berechnungen anzustellen.

Weiterhin empfiehlt die DNA-Kommission der ISFG für gutachterliche Stellungnahmen die Verwendung unmissverständlicher Formulierungen, die klarstellen, auf welcher Hierarchieebene biostatistische Berechnungen durchgeführt und entsprechende Aussagen getroffen werden. Dadurch kann vermieden werden, dass ein imponierend hoher Zahlenwert, der als „likelihood ratio“ auf der Identitätsebene berechnet wurde, unzulässigerweise auf eine höhere Ebene übertragen wird [5, $9,10]$. In dem oben genannten Beispiel der zerbrochenen Scheibe kann es zwar über $30 \mathrm{Mrd}$. Mal wahrscheinlicher sein, das nachgewiesene DNA-Profil der Spur zu beobachten, wenn die DNA in der Spur von Person $X$ stammt, als wenn sie von ei- ner unbekannten Person stammt. Es wäre jedoch ein Fehler anzunehmen, dass es ebenso viel wahrscheinlicher ist, dass die Blutspur beim Einschlagen der Scheibe entstanden ist, als dass sie durch eine Verletzung durch eine bereits zerbrochene Scheibe verursacht wurde. Eine solche direkte Übertragung von Wahrscheinlichkeiten auf eine höhere Hierarchieebene, in diesem Fall von der Identitäts- auf die Aktivitätsebene, ist nicht zulässig und birgt die Gefahr der Fehleinschätzung, i.d.R. eine Überinterpretation des Beweiswertes der Spur auf Aktivitätsebene [11].

In Deutschland wird die überwiegende Zahl der Aufträge an die DNA-Untersuchungsstellen unmittelbar durch die Polizei erteilt. In vielen Fällen und hier insbesondere im Bereich der Massenkriminalität enthalten die Aufträge an die Untersuchungsstellen keine bzw. keine relevanten oder nichtausreichende Informationen, um eine Bewertung der Spuren auf Aktivitätsebenezu erlauben. Bewertungen auf Aktivitätsebene sind in dieser sehr frühen Ermittlungsphase i. d. R. auch nicht beauftragt. Aussagen, die Sachverständige in entsprechenden Gutachten treffen, beziehen sich daher fast ausschließlich auf die Ebenen der Identität und des Ursprungs des zu untersuchenden Spurenmaterials (z. B. Handelt es sich bei dem gesicherten Spurenmaterial um Humanblut, und von wem stammt das Blut?). Zur Klarstellung, dass Befunde lediglich auf Identitätsebene und ggf. Ursprungsebene, nicht jedoch auf Aktivitätsebene interpretiert wurden, können Sachverständige in ihren Gutachten eine entsprechende Einschränkung einfügen.

Für Gerichte ist aber häufig nicht die Identitäts- oder Ursprungsebene, sondern im Wesentlichen die Aktivitätsebene für die Frage nach der Schuld oder Unschuld relevant. Daher stellt sich spätestens im Rahmen der Hauptverhandlung die zentrale Frage, ob eine DNA-Spur in unmittelbarem Zusammenhang zur Tat oder durch eine "unschuldige" Handlung ohne Tatbezug entstanden ist.

Die beiden Fragen

- Von wem stammt die DNA? und

- Wie und wann kam die DNA an den Tatort? 
müssen unabhängig voneinander beurteilt werden. Nach Aufforderung kann der forensische Sachverständige das Gericht ggf. auch auf Aktivitätsebene sachverständig beraten. Grundsätzlich gilt, dass eine (latente) DNA-Spur vor, während oder nach einer Tat gelegt bzw. angetragen worden sein kann. Dabei ist sowohl ein direkter als auch ein indirekter Spurentransfer möglich. Für eine strukturierte Beratung auf Aktivitätsebene muss dem Sachverständigen im Bedarfsfall eine Beschreibung alternativer Erklärungen für das Zustandekommen der Spur vorgegeben werden.

\subsection{Wie kam die DNA an den Tatort? - Situation vor der Tat}

Die Möglichkeit, dass DNA einer Person, die bereits zu einem früheren Zeitpunkt berechtigten Zugang zum späteren Tatort oder beispielsweise einem Tatwerkzeug hatte, an einem Tatort nachgewiesen wird, muss aufgrund der Persistenz von DNA unter bestimmten Umweltbedingungen ggf. als alternative Entstehungsmöglichkeit in Betracht gezogen werden. Die mit der Spurenuntersuchung beauftragten DNA-Sachverständigen haben aber größtenteils keine oder nur wenig Kenntnis über legale Zugänge zum Tatort oder den dort aufgefundenen Spurenträgern, sodass sie üblicherweise keine belastbare Aussage hierüber treffen können.

Ein Beispiel: Im Jahr 2007 wurde in einer norditalienischen Kleinstadt die Britin Meredith Kercher erstochen in ihrem WG-Zimmer aufgefunden. Mittatverdächtig war eine ihrer Mitbewohnerinnen, Amanda Knox. Unter anderem war im Waschbecken des gemeinsam genutzten Badezimmers eine Blutspur mit DNA-Spurenanteilen der beiden Frauen gefunden worden (eine detaillierte Betrachtung der Umstände in diesem Verfahren findet sich in [12]). In der erstinstanzlichen Verurteilung wurden diese DNA-Befunde als Beweis dafür gedeutet, dass Amanda Knox das Tatmesser benutzte, um Meredith Kercher zu erstechen und anschließend im Badezimmer das Blut abzuwaschen, wodurch die Mischspur aus ihrer und der DNA des Opfers entstand. Die Befunde führten auf der Identitätsebene zu unstrittigen Zuordnungen, wurden jedoch seitens der Strafverfolgungsbehörden auf der Ursprungs- und Aktivitätsebene interpretiert. Aufgrund des Zusammenlebens der beiden Frauen in einer Wohnung und gemeinsamer Nutzung des Badezimmers ist eine nicht im Tatzusammenhang stehende Spurenübertragung ebenfalls denkbar.

\subsection{Wie kam die DNA an den Tatort? - Handlungen im Tatzusammenhang}

Die Praxis zeigt, dass in aktuellen Strafverfahren immer häufiger auch die Möglichkeit eines indirekten DNA-Transfers im Tatzusammenhang, aber ohne konkreten Tatbezug als Erklärung der Spurenentstehung diskutiert wird. Dies trifft häufig für isoliert auftretende, latente DNA-Spuren zu, deren Ursprung nicht nachgewiesen werden konnte, da es sich z. B. um mögliche Hautabriebspuren (Kontaktspuren) handelt. Die Anzahl weiterer, am Tatort aufgefundener Spuren einer nichttatortberechtigten, beschuldigten Person kann die Einschätzung beeinflussen, ob es sich eher um einen direkten oder indirekten DNA-Transfer handelt. Das Tatgericht wird im Rahmen seiner Beweiswürdigung zu prüfen haben, ob es aus der Anzahl der am Tatort aufgefundenen Spuren einen Rückschluss auf den Grad der Wahrscheinlichkeit der DNAÜbertragung im Tatzusammenhang zu ziehen vermag.

Ein weiteres Beispiel: Im Rahmen der Verhandlung eines Einbruchsdeliktes stand der Beweiswert zweier übereinstimmender DNA-Spuren zur Debatte. Diese waren zuvor am Griff eines Schrauben- drehers sowie an der Außenseite von Handschuhen gesichert worden, die am Tatort aufgefunden worden waren. Bei dem Schraubendreher sollte es sich um das Tatwerkzeug handeln, und die Handschuhe sollen möglicherweise bei der Tat vom Täter getragen worden sein. Das festgestellte DNA-Profil führte über eine Recherche in der DAD zu einem Treffer mit dem DNA-Profil des nun Angeklagten. Dieser gab an, dass er die Handschuhe vermisst habe und ein Unbekannter die Tat ausgeführt haben müsse. Die Spur am Schraubendreher wäre somit auf einen "Sekundärtransfer" der DNA-Spur an den Schraubendreher zurückzuführen.

Unter Sekundär- oder besser indirektem DNA-Transfer versteht man im forensischen Kontext Szenarien, bei denen die DNA einer Person nicht unmittelbar durch sie selbst, sondern indirekt (z.B. von Person 1 zu Person 2 und anschließend von Person 2 an den Tatort) übertragen wurde. Auch mehrstufige Übertragungen, z. B. von Person 1 zu einem Objekt, anschließend vom Objekt zur Person 2 und schließlich von Person 2 zum Tatort oder über beliebig viele weitere Zwischenstufen (-Abb. 2), werden unter dem Begriff des indirekten Transfers zusammengefasst.

Zahlreiche Laborstudien belegen inzwischen, dass DNA-Spurenmaterial über verschiedenste Szenarien von einer Person oder einem Gegenstand auf eine andere Person oder einen anderen Gegenstand übertragen werden kann [13]. Diese Erkenntnis sollte sich somit auch in der gutachterlichen Bewertung einer DNA-Spur auf Aktivitätsebene niederschlagen. Das
Hier steht eine Anzeige.

$$
\text { 黛 Springer }
$$




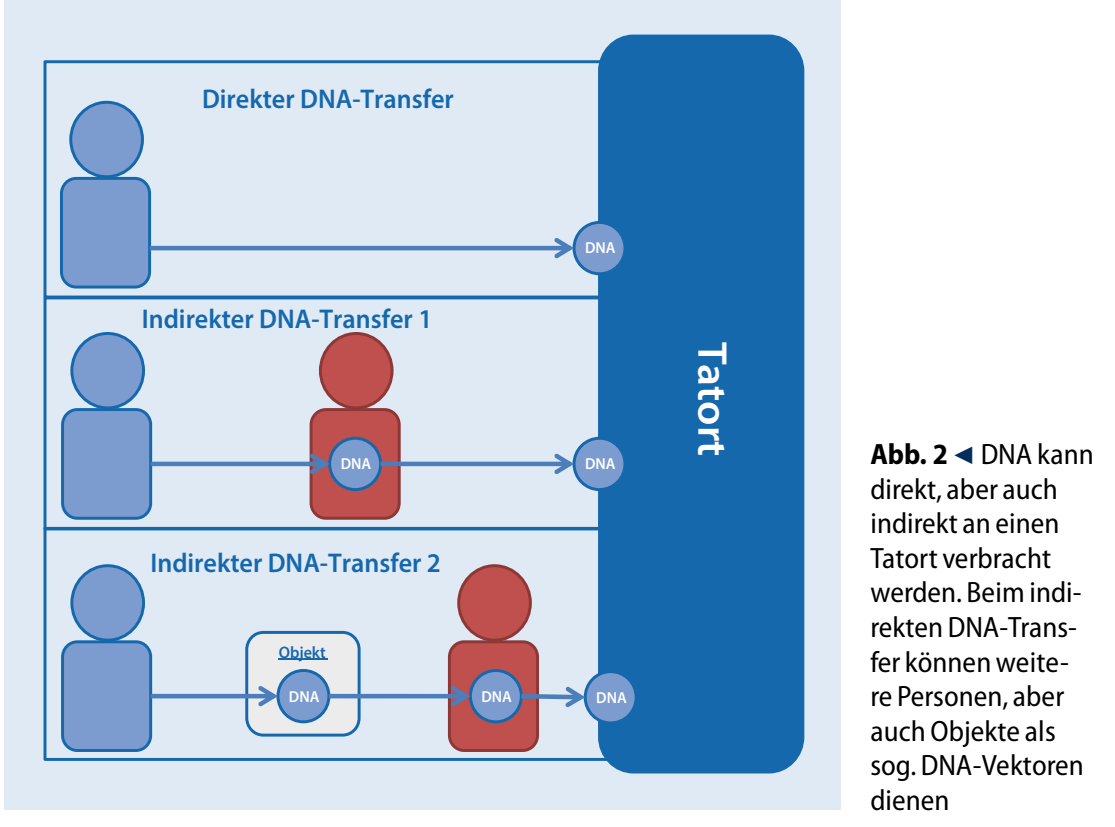

Vorhandensein einer DNA-Spur gibt nur in seltenen Fällen Auskunft über den möglichen Übertragungsweg. Insbesondere bei nichtgetrockneten, noch flüssigen Körperflüssigkeiten (Blut, Sperma, Speichel) sind auch nach einem Transferereignis gut interpretierbare DNA-Befunde zu erwarten, die von direkt übertragenen Spuren nicht zu unterscheiden sind.

Bei latenten DNA-Spuren, bei denen das zugrunde liegende Körpergewebe/-sekret i.d.R. nicht bekannt ist, lässt die Intensität der Spur möglicherweise einen eingeschränkten Rückschluss auf den Übertragungsweg zu. Da bei jedem möglichen Transfer realistisch nur ein Teil der DNAMenge übertragen wird, sind insbesondere DNA-Spuren mit hohem DNA-Gehalt und vollständig nachweisbaren DNA-Profilen über einen direkten Transfer häufig plausibler zu erklären als durch einen indirekten Transfer. Dies gilt insbesondere für Spuren, die DNA einer einzelnen Person enthalten, da bei einem Transferereignis durch eine Person oder einen Gegenstand die DNA oft nicht selektiv weitergegeben wird, sondern sich dort mit der bereits vorhandenen Hintergrund-DNA zu einer Mischung vereint [14-16].

DNA-Sachverständige besitzen i.d.R. kein oder nur wenig Hintergrundwissen über die Tatumstände, die Örtlichkeit oder die Beziehungen der involvierten Personen zueinander. Schon aus diesem Grund sind pauschale Aussagen bzgl. eines mög- lichen indirekten Transferereignisses für den Einzelfall nur sehr begrenzt möglich. Aber auch bei detaillierten Kenntnissen können auf Grundlage des derzeitigen Wissenstands nur für spezielle Szenarien valide Aussagen getroffen werden.

Zum Thema "indirekter DNA-Transfer" existiertmittlerweile eine Fülle an Literatur, die sich mit dem Einfluss unterschiedlichster Faktoren (Oberflächenbeschaffenheit, individuelle Fähigkeit der beteiligten Personen, Hautschuppen abzugeben [engl. "shedder status"], Intensität und Dauer von Berührungen usw.) beschäftigt (Übersicht z. B. in [17]) und zudem eine breite methodische Vielfalt aufweist. Die intensive Forschungsarbeit auf diesem Gebiet ermöglicht zudem immer detailliertere Einblicke in die komplexen Zusammenhänge bei DNA-Transferereignissen. Sie verdeutlicht zum anderen aber auch den noch erheblichen Studienaufwand, um die Wahrscheinlichkeit des indirekten DNA-Transfers in unterschiedlichen Szenarien zu schätzen. Ein annähernd vollständiges Verständnis aller Einflussfaktoren ist jedoch die Grundlage möglicher (vor allem biostatistischer) Bewertungen unter Annahme verschiedener konkreter Hypothesen durch Sachverständige $[10,11]$.

Aufgrund der Vielzahl publizierter Studien ist nicht zu erwarten, dass Sachverständige alle Literaturdaten zu beliebigen Szenarien verfügbar haben und ad hoc auf die konkrete Fallsituation anwenden können. Auf der Grundlage einer gezielten Literatursuche kann sie/er aber ggf. einschätzen, ob und in welcher Form eine Begutachtung möglich und sinnvoll ist. Dabei wird es nur in sehr seltenen Fällen valide Literaturdaten zu den in einem spezifischen Verfahren formulierten Hypothesen geben, die vollständig auf den zu begutachtenden Fall übertragen werden können und eine statistische Bewertung ermöglichen. Ggf. werden Sachverständige dennoch verbale Einschätzungen vornehmen können. Diese beruhen auf der Kenntnis vergleichbarer Szenarien aus publizierten Studien und können neben den zur Diskussion stehenden Aktivitäten auch die Qualität und Quantität der gefundenen DNA-Antragungen sowie die zeitlichen und räumlichen Umstände der Spurenentstehung berücksichtigen. Objektivierbare Daten aus geplanten Experimenten sowie die wissenschaftliche Literatur stellen die wichtigsten Informationsquellen für Sachverständige dar [9] und sachverständige Aussagen sollten, wo immer möglich, darauf beruhen. Unter Umständen kann es jedoch notwendig sein, auch die eigene praktische Erfahrung sowie den "gesunden Menschenverstand" mit in die Abwägungen einzubeziehen. Einschätzungen, die nicht auf spezifisch sachverständiger Kenntnis beruhen, müssen jedoch als solche qualifiziert werden.

\subsection{Wie kam die DNA an den Tatort? - Aktivitäten nach der Tat (Kontamination)}

Bei einer unbeabsichtigten Übertragung von DNA-Spuren, die frühestens ab dem Zeitpunkt der (polizeilichen) Spurensicherung erfolgt, z.B. bei der Probennahme am Tatort, beim Ein- und Auspacken von Gegenständen oder bei der Spurenanalyse im DNA-Labor, spricht man von Kontaminationen. Es kann sich dabei sowohl um direkte als auch um indirekte Transferereignisse handeln. Ein Beispiel für eine direkte Übertragung ist das ungeschützte Sprechen während der Spurensicherung über einem gesicherten Gegenstand. Hierbei können Speicheltröpfchen auf diesen Gegenstand übertragen werden. Die so übertragene DNA kann in einem solchen Fall zu einer Vermischung mit ursprünglich an dem Gegenstand vorhandener 
DNA führen, ggf. diese auch vollständig überlagern. Die Übertragung von DNA von einem Untersuchungsgegenstand auf einen anderen, z.B. durch nichtgewechselte Handschuhe, wäre dagegen ein Beispiel für eine Kontamination durch einen indirekten Transfer [18, 19]. Kontaminationen durch Personen, die mit den verschiedenen Schritten der Spurensicherung, der Handhabung von Proben und der Laboranalyse betraut sind, aber auch durch andere tatort- und laborberechtigte Personen, können in den nach DIN EN ISO/IEC 17025 akkreditierten DNA-Untersuchungsstellen durch die konsequente Nutzung von Einwegmaterialien weitestgehend vermieden und in Kombination mit dem Einsatz von Datenbanken, die die DNA-Profile dieser Personen enthalten, frühzeitig erkannt werden [20]. Zur weiteren Minimierung des Kontaminationsrisikos im Verlauf einer DNA-Analyse existieren in den Untersuchungsstellen im Rahmen des Qualitätsmanagements zahlreiche Vorschriften, deren Einhaltung kontinuierlich überwacht wird. Regelmäßige Schulungen der spurensichernden Organisationseinheiten ergänzen die etablierten Strategien zur Kontaminationsvermeidung.

\section{Formulierung von Hypothesen auf Aktivitätsebene}

Auf der Identitätsebene können Sachverständige auf umfassende populationsgenetische Daten zurückgreifen, die valide, allgemein anerkannt und öffentlich zugänglich sind (https://strider.online/). Im Gegensatz dazu erfordert die Formulierung von Hypothesen auf Aktivitätsebene i.d.R. die Berücksichtigung einer Vielzahl von situations- und umweltabhängigen Faktoren, die neben der eigentlichen Aktivität (d.h. der Handlung, die zur Platzierung einer DNA-Spur führte) folgende Parameter umfassen können: Art des Spurenmaterials, DNA-Menge und -Qualität (z.B. Degradierung), Beschaffenheit von Oberflächen und damit deren Fähigkeit, Spurenmaterial aufzunehmen und wieder abzugeben, Umwelteinflüsse (Temperaturen, Wetter, Mikroorganismen), aber auch den Zeitpunkt der Spurenentstehung. In den vergangenen Jahren wurden zahlreiche Studien zu einzelnen, teilweise sehr speziellen, Fallkonstellationen veröffentlicht. Die Literatur kann jedoch nicht zu allen theoretisch möglichen Fallszenarien ausreichend valide Daten bieten, was in vielen Fällen eine Beurteilung einschränkt oder gänzlich unmöglich machen kann. Die DNA-Kommission der ISFG erarbeitete kürzlich Empfehlungen zur Formulierung von Hypothesen auf Aktivitätsebene, die für das Gericht hilfreich, dem tatsächlichen Fall entsprechend und so konkret und so kurz wie möglich sein sollen [9]. Es gibt eine Vielzahl denkbarer Szenarien, die in konkreten Strafverfahren vorgebracht werden können, um die Entstehung einer in Bezug auf den Angeklagten „beweiskräftigen" Spur durch weniger belastende Umstände zu erklären. Daher ist nicht zu erwarten, dass es in Zukunft für jedwede Fallkonstellation umfassende und belastbare Daten geben wird. Somit werden die verfügbaren Daten i.d. R. immer nur eine Annäherung an das postulierte Geschehen erlauben.

Zur Verdeutlichung soll das oben beschriebene Fallbeispiel nochmals näher betrachtet werden: Nach einem Einbruch wurde ein mit dem DNA-Profil des Angeklagten übereinstimmendes DNA-Profil an einem Schraubendreher nachgewiesen, der zusammen mit Handschuhen am Tatort aufgefunden wurde. Staatsanwaltschaft, Verteidigung und das Gericht sind sich in der Annahme einig, dass es sich bei dem Schraubendreher um das Tatwerkzeug handelt, mit dem eingebrochen wurde.

Im Verlauf des Strafverfahrens wurden nun verschiedene Erklärungen für das Vorliegen des DNA-Profils des Angeklagten am Tatwerkzeug angeführt. Die zunächst naheliegende Erklärung lautet: „Der Angeklagte benutzte den Schraubendreher zum Aufhebeln des Fensters". Eine alternative Erklärung könnte einen indirekten DNA-Transfer beinhalten, z. B.: „Der wahre Täter (nicht der Angeklagte) benutzte den Schraubendreher zum Aufhebeln des Fensters und trug dabei Handschuhe, die aus dem Besitz des Angeklagten stammen und die dieser zuvor benutzt hatte. Die DNA des Angeklagten wurde über die Außenseite der Handschuhe indirekt an das Tatwerkzeug übertragen". Weitere Erklärungen sind denkbar, z.B.: „Der Schraubendreher stammt aus dem Besitz des Angeklagten, der wahre Täter benutzte den Schraubendreher zum Aufhebeln des Fensters und trug dabei Handschuhe, die eine Antragung seiner eigenen DNA verhinderten". Hier wird deutlich, dass die Suche nach Erklärungen zur Spurenentstehung unter Umständen spekulativ werden kann. Um eine gutachterliche Einschätzung zu ermöglichen, muss im Verfahren zunächst eine Einigung über zwei spezifische, sich gegenseitig ausschließende Hypothesen erfolgen, die in die Begutachtung einbezogen werden sollen. Im vorliegenden Fall könnte man sich beispielsweise auf folgende Hypothesen einigen:

- H1: „Die DNA des Angeklagten wurde direkt durch intensive Benutzung auf den Schraubendreher übertragen."

- H2: „Die DNA des Angeklagten wurde indirekt auf den Schraubendreher übertragen, indem eine andere Person Handschuhe trug, an die DNA des Angeklagten von außen angetragen war, und damit den Schraubendreher intensiv nutzte."

Es wird deutlich, dass die "Aktivität" sich lediglich auf die Nutzung des Schraubendrehers beschränken muss. Ob diese Nutzung tatsächlich das Aufhebeln des Fensters beinhaltet, lässt sich allein aufgrund des DNA-Befundes nicht beurteilen.

Bei der Beurteilung wird nun betrachtet, mit welcher Wahrscheinlichkeit die Beobachtung der DNA-Spur am Schraubendreher zu erwarten ist, wenn jeweils eine der beiden Hypothesen wahr sei. Bei der Beurteilung wird nicht die Plausibilität der Szenarien selbst betrachtet, sondern lediglich, inwieweit diese Szenarien die Wahrscheinlichkeit der Beobachtung des DNA-Befundes beeinflussen. Um diese Wahrscheinlichkeiten unter Annahme der jeweiligen Hypothesen abzuschätzen, müssen valide Informationen aus der Literatur zu zahlreichen Einzelaspekten verfügbar sein. Neben der Objektivierung des Begriffs „intensiv“ stellt sich zunächst die Frage, wie häufig eine Person 1, die einen Schraubendreher ohne Handschuhe nutzt, DNA am Griff hinterlassen wird. Dabei spielen die Art und Dauer des Anfassens, aber auch die Beschaffenheit des Griffs und, ob die Person 1 ein guter oder schlechter Shedder (Glossar; [21]) ist, eine wichtige Rolle. Auch darf nicht außer Acht gelassen 
werden, ob sich durch eine vorangegangene Benutzung bereits DNA-Material an dem Schraubendreher befand.

Darüber hinaus müsste ggf. geprüft werden, wie häufig die DNA einer Person 2, die zuvor die Handschuhe getragen hat, an der Außenseite der Handschuhe zu finden ist. Dabei spielt die Beschaffenheit der Handschuhe eine wichtige Rolle, aber auch, wie lange und intensiv sie zuvor von Person 2 getragen wurden, welche Handlungen beim Tragen der Handschuhe ausgeübt wurden (z. B. Abwischen des Gesichts), und ob diese Person ein guter oder schlechter Shedder ist. Abschließend müssen Daten dazu erhoben werden, wie häufig DNA von Handschuhen auf einen Schraubendreher beim Anfassen desselben übertragen und anschließend auch detektiert wird. Dabei sind sowohl die DNA-Menge und die Spurenart als auch die Beschaffenheit der Materialien von Bedeutung.

Basierend auf diesem Fallbeispiel wurden in einer kürzlich veröffentlichten Studie ein Teil der genannten Aspekte (Shedder status, verwendete Materialien, Art und Zeit des Tragens der Handschuhe sowie des Gebrauchs des Schraubendrehers) aufgegriffen und das Szenario unter streng definierten Vorgaben nachgestellt [22]. Unter den festgelegten Testbedingungen zeigte sich, dass die Beobachtung eines DNA-Profils von guter Qualität etwa siebenmal wahrscheinlicher zu erwarten ist, wenn Hypothese $\mathrm{H} 1$ (direkter DNATransfer) und nicht Hypothese $\mathrm{H} 2$ (indirekter DNA-Transfer über Handschuhe) wahr ist. Eine direkte Übertragung des in der Studie erzielten Wahrscheinlichkeitswerts auf das oben skizzierte Fallbeispiel wäre aber auch dann nicht möglich, wenn die festgelegten Testbedingungen das geschilderte Szenario vollständig widerspiegeln würden, da weitere Einflussfaktoren existieren könnten, die in den Versuchsreihen nicht abgebildet wurden. Die Ergebnisse liefern somit lediglich Anhaltspunkte, die in eine abwägende verbale Sachverständigenbeurteilung einfließen können. Auch hier zeigt sich, dass die Möglichkeit der Nutzung der im Rahmen einer Studie gewonnenen Erkenntnisse in konkreten Fallkonstellationen begrenzt ist. Es sollte weiterhin nicht außer Acht gelassen werden, dass diese Annäherung lediglich die beiden in den Hypothesen skizzierten Szenarien abdeckt und die Möglichkeit besteht, dass die "Wahrheit" über die Entstehung der Spur in keiner der beiden Hypothesen enthalten war.

\section{Fazit}

DNA-Spuren können auf verschiedenen Ebenen interpretiert werden. Zur Einordnung des Stellenwerts eines DNA-Ergebnisses empfehlen wir die Betrachtung der Spuren auf diesen verschiedenen Ebenen im Sinne des Konzepts der "Hierarchie der Hypothesen". Auf Identitäts- und Ursprungsebene können Zuordnungen von Spuren zu Personen sowie Aussagen über den zellulären Ursprung der Spur getroffen werden. Fragen zur Spurenentstehung werden auf der Aktivitätsebene gestellt und betreffen den Zeitpunkt der Spurenentstehung (vor, während oder nach einer Tat) sowie die Möglichkeit verschiedener Transferszenarien. Auf Deliktsebene schließlich trifft das Gericht seine Entscheidung. Zusammenfassend lassen sich folgende Kernaussagen formulieren, die sowohl von Sachverständigen als auch von allen an einem Verfahren beteiligten Juristen beachtet werden sollten:

- Staatsanwaltschaften und Gerichte sollten sich in der Beauftragung und Befragung durch das Gericht bewusst sein, auf welcher Hierarchieebene der Sachverständige im Einzelfall eine Einschätzung geben kann.

- Der DNA-Befund bietet bei Betrachtung auf Identitätsebene weder Informationen über Mechanismen oder Handlungen, die zur Entstehung der DNA-Spur führten, noch zum Zeitpunkt der Spurenentstehung.

- Wenn die DNA-Menge einer Spur sehr gering ist und die postulierten Aktivitäten, die zu der Spurenentstehung geführt haben, umstritten sind, dann haben Transfer, Persistenz und Hintergrund-DNA einen starken Einfluss auf die Gesamtbewertung.

- Eine Spur muss nicht zwingend in direktem Zusammenhang mit einer Straftat gelegt worden sein, sie kann auch vor oder nach der Tat entstanden oder indirekt an den Tatort verschleppt worden sein.
- Während das Vorliegen von Hinweisen auf DNA einer Person in mehreren Spuren eher auf eine direkte Übertragung der DNA hindeuten kann, sollte bei Vorliegen eines Hinweises in nur einer einzelnen Spur, insbesondere mit niedrigem DNA-Gehalt, stets auch die Möglichkeit eines indirekten DNATransfers in Betracht gezogen werden.

- Indirekter DNA-Transfer kann ein realistisches Szenario zur Erklärung der Spurenentstehung darstellen. In der wissenschaftlichen Literatur werden Szenarien des indirekten DNA-Transfers beschrieben, jedoch zeigen diese Studien, dass der direkte DNA-Transfer häufiger zu einer auswertbaren DNASpur führt als der indirekte DNATransfer. Folglich lassen sich Spuren mit hohem DNA-Gehalt und vollständig nachweisbaren DNA-Profilen i.d. Rüber einen direkten Transfer besser erklären als durch einen indirekten Transfer.

- Grundsätzlich gilt, dass die DNA-Menge mit jedem Transferereignis abnimmt, und dass die Wahrscheinlichkeit für das Vorliegen von Mischspuren mit jedem Transferschritt zunimmt.

- Nach gesonderter Beauftragung können Sachverständige verschiedene durch den Auftraggeber formulierte alternative Szenarien, die das Zustandekommen eines spezifischen DNABefundes auf der Aktivitätsebene erklären könnten, vergleichend betrachten. Hierzu nutzen sie - soweit vorhanden - publizierte, wissenschaftlich erhobene Daten aus empirischen, prospektiven Studien, die die spezifische Fragestellung behandeln.

- Es ist für eine zielorientierte Sachverständigentätigkeit unabdingbar, dass Hypothesen zur Spurenentstehung von den Verfahrensbeteiligten formuliert werden, und dass vor Beauftragung des Sachverständigen über bestimmte Erklärungsmodelle (bspw. zwei alternative Szenarien) Einigkeit herrscht. Eine Änderung dieser Erklärungen im laufenden Verfahren kann dazu führen, dass Sachverständige eine (neue) Betrachtung basierend auf einem (erneuten) Literaturstudium erarbeiten müssen. Aufgrund der ständig wachsenden Zahl verfügbarer Literaturquellen ist von Sachverstän- 
digen nicht zu erwarten, eine solche Einschätzung spontan im Gerichtssaal durchzuführen.

- In den allermeisten Fällen werden Sachverständige aufgrund fehlender, exakt passender Studien kein wahrscheinlichkeitsgestütztes Verfahren anwenden können, um DNA-Spuren auf der Aktivitätsebene zu beurteilen. Unter Umständen kann aber eine verbale Einschätzung erfolgen, der eigene Erfahrungen, Erkenntnisse aus der Fachliteratur oder eigene Studien zugrunde liegen. Es treten jedoch immer wieder Fälle auf, in denen Sachverständige auch keine verbale Gewichtung vornehmen können, nämlich immer dann, wenn von den Verfahrensbeteiligten keine ausreichend konkreten Hypothesen zur Spurenentstehung formuliert werden können oder sich in der Literatur keine vergleichbaren Studien finden.

- Die Beauftragung fallbezogener Studien zur Bewertung alternativer Szenarien der Spurenentstehung ist aus Sicht der Autoren nur selten zweckdienlich, da gemeinhin aufgrund der Vielzahl möglicher Einflussfaktoren nicht alle Randbedingungen ausreichend definiert bzw. adäquat in der Studie abgebildet werden können.

- In Ausnahmefällen kann es notwendig sein, dass der Sachverständige neben seiner spezifisch sachverständigen Kenntnis auch auf den "gesunden Menschenverstand" zurückgreifen muss, beispielsweise um einzelne Parameter der Handlung zu schätzen (z. B. Intensität des Anfassens bei Benutzung von Werkzeugen). Sachverständige sollen Einschätzungen, die nicht auf spezifisch sachverständiger Kenntnis beruhen, eindeutig von sachverständiger Erfahrung abgrenzen.

\section{Glossar $^{1}$}

"DNA-TPPR" „DNA transfer, prevalence, persistence, recovery". Dieses Kürzel wird in der internationalen Fachliteratur häufig genutzt. Es steht für verschiedene zentrale Aspekte, die mit dem Themenkomplex "Übertragung von DNA“ zu tun haben. Die Verwendung der einzelnen Begriffe im Kontext des Themenkomplexes wird im Folgenden erläutert.

„Transfer" grundsätzlichals Oberbegriffverwendet für jede Übertragung von DNA. Von DNA-Transfer im engeren Sinne spricht man, wenn die DNAÜbertragung zu einem Zeitpunkt vor, in Verbindung mit oder nach dem Tatgeschehen, aber vor der eigentlichen Spurensicherung stattgefunden hat.

"Direct/primary transfer" DirekterTransfer/ direkte Übertragung: Übertragung von DNA durch direkten Kontakt der Person, von der die DNA stammt, mit einem Gegenstand. Beispiel: Eine Person A trinkt aus einer Flasche; DNA dieser Person wird am Flaschenhals festgestellt.

„Indirect transfer“ Indirekter Transfer/indirekte Übertragung: Jede weitere Übertragung von DNA auf einen Gegenstand, mit dem die entsprechende Person keinen direkten Kontakt hatte. Beispiel: Jemand reibt mit einem Taschentuch den o. g. Flaschenhals ab. An dem Taschentuch befindet sich nun DNA der Person A, obwohl diese mit dem Taschentuch keinen Kontakt hatte.

"Secondary transfer" Sekundärtransfer/ Sekundärübertragung: Dieser Begriff sollte möglichst vermieden werden, da die Verwendung in der Literatur nicht eindeutig ist: fer".

1. Als Oberbegriff, analog zum „indirect trans-

2. Im engeren Sinne: zweiter (indirekter) Transferschritt nach dem ersten (direkten) Transfer. Weitere Übertragungsschritte werden dann als Tertiärtransfer, Quartärtransfer usw. bezeichnet.

„Prevalence" Prävalenz, Vorhandensein, „Verbreitung" von DNA: Hier geht es vor allem darum festzustellen, ob und in welchem Maße „üblicherweise" an bestimmten Gegenständen DNA nachweisbar ist. Zum einen handelt es sich um DNA, die am entsprechenden Ort der Spurensicherung zu erwarten ist (z. B. eigene DNAan getragener Kleidung oder an Werkzeugen aus dem eigenen Besitz). Ebenso ist hier von Interesse, inwieweit sich an Kleidungsstücken, Körperteilen (z. B. Händen) usw. DNA befindet, die nicht von der Person selbst stammt.

„Persistence" Überdauern/„,Haltbarkeit“/ Beständigkeit von DNA: Dieser Aspekt beschäftigt sich damit, wie lange DNA an einem fraglichen Gegenstand nachweisbar ist, abhängig von unterschiedlichen Faktoren. Hier geht es z. B. um Umweltfaktoren (Wetter, UV-Licht), (mikrobielle) Abbauprozesse (z. B. von Spermien nach Vaginalverkehr), Handhabung eines Gegenstandes, Reinigung von Kleidungsstücken usw.

\section{Zum DNA-Transfer}

In der englischsprachigen Fachliteratur zum Thema "DNA-Transfer" sind verschiedene Begriffe geläufig, für die es bislang noch keine einheitliche deutsche Definition gibt. Weiterhin werden nachfolgend typische Begriffe der DNA-Analyse mit Relevanz für das Thema "DNA-Transfer" erläutert.
„Recovery“ Wiederfindungsrate: Unter diesem Aspekt werden z. B. die Art und Effektivität der Spurensicherung (z. B. das Fertigen von Abrieben, Abklebungen, direkte Probennahme) sowie die Effektivität der folgenden Analyseschritte bis zur Erstellung von DNA-Profilen zusammengefasst.

DNA-Profil/DNA-Identifizierungsmuster Basis eines sog. DNA-Profils ist die Analyse einer Anzahl von "short tandem repeats" (STR). Es handelt sich dabei um Bereiche der DNA mit kurzen tandemartig angeordneten Wiederholungsmotiven aus 3 bis 5 DNA-Bausteinen, die bei unterschiedlichen Personen unterschiedliche Längen aufgrund einer unterschiedlichen Anzahl von Wiederholungseinheiten haben können. Die festgestellten Fragmentlängen werden in Form einer Zahlenkombination dargestellt, die die Anzahl der jeweils vorliegenden Wiederholungen repräsentieren. Die untersuchten Bereiche der DNA werden als Marker- oder Merkmalssysteme bezeichnet, die festgestellten Werte als Allele.

Einzelspur/Einzelprofil/Reinspur Im Rahmen der DNA-Analyse wurden in der Mehrzahl der untersuchten Markersysteme ein oder zwei Allele detektiert. Diese Ergebnisse sind vereinbar mit der Annahme eines einzelnen Spurenverursachers.

Mischspur/Mischprofil Im Rahmen der DNA-Analyse wurden in mehreren Markersystemen mehr als zwei Allele nachgewiesen. Die Mindestzahl an Spurenverursachern kann anhand der maximalen Zahl nachgewiesener Allele pro DNA-Merkmalssystem geschätzt werden.

„Background DNA“ Hintergrund-DNA:Dieser Begriff wird nicht einheitlich verwendet. Er beschreibt z. B. DNA, die sich unabhängig vom Tatgeschehen bereits am betreffenden Ort oder dem betreffenden Gegenstand befunden hat, und kann daher auch die „prevalence" einschließen.

Kontamination Bei einer Kontamination handeltes sich grundsätzlich um den gleichen Vorgang wie bei einem Transfer. Es handelt sich hier aber um eine Übertragung von DNA, die nicht mit der Straftat zusammenhängt und zeitlich frühestens $a b$ dem Zeitpunkt der polizeilichen Spurensicherung erfolgt (z. B. bei der Probennahme, bei der Verpackung von Gegenständen, bei der Spurenanalyse im DNA-Labor).

"Likelihood" Bewertung eines beobachteten Ereignisses auf der Grundlage einer Hypothese (eines wahrscheinlichkeitstheoretischen Modells): Eine "Likelihood" geht von einer Feststellung aus (z. B. dem Nachweis von DNA einer Spur, deren Profil mit dem DNA-Profil einer Person übereinstimmt) und beschreibt nachträglich die Beobachtungswahrscheinlichkeit für das DNA-Profil unter einer möglichen Erklärung (Hypothese).

"Shedder" Abgeber/Überträger von Hautkontaktspuren.

"Shedder status" („good/bad shedder“) Beschreibt ob eine Person bei Hautkontaktspuren ein guter oder schlechter Spurengeber ist.

Korrespondenzadresse

\section{Peter M. Schneider}

Institut für Rechtsmedizin, Medizinische Fakultät und Universitätsklinik, Universität zu Köln

Melatengürtel 60/62, 50823 Köln, Deutschland peter.schneider@uk-koeln.de 
Danksagung. Die Autoren bedanken sich bei Frau Martina Bogner, München, und Frau Dr. Theresa Groß, Wiesbaden, für hilfreiche Diskussionen und Kommentare zum vorliegenden Text.

Funding. Open Access funding enabled and organized by Projekt DEAL.

\section{Einhaltung ethischer Richtlinien}

Interessenkonflikt. Die Autoren geben an, dass kein Interessenkonflikt besteht.

Für diesen Beitrag wurden von den Autoren keine Studien an Menschen oder Tieren durchgeführt. Für die aufgeführten Studien gelten die jeweils dort angegebenen ethischen Richtlinien.

Open Access. Dieser Artikel wird unter der Creative Commons Namensnennung 4.0 International Lizenz veröffentlicht, welche die Nutzung, Vervielfältigung, Bearbeitung, Verbreitung und Wiedergabe in jeglichem Medium und Format erlaubt, sofern Sie den/die ursprünglichen Autor(en) und die Quelle ordnungsgemäß nennen, einen Link zur Creative Commons Lizenz beifügen und angeben, ob Änderungen vorgenommen wurden.

Die in diesem Artikel enthaltenen Bilder und sonstiges Drittmaterial unterliegen ebenfalls der genannten Creative Commons Lizenz, sofern sich aus der Abbildungslegende nichts anderes ergibt. Sofern das betreffende Material nicht unter der genannten Creative Commons Lizenz steht und die betreffende Handlung nicht nach gesetzlichen Vorschriften erlaubt ist, ist für die oben aufgeführten Weiterverwendungen des Materials die Einwilligung des jeweiligen Rechteinhabers einzuholen.

Weitere Details zur Lizenz entnehmen Sie bitte der Lizenzinformation auf http://creativecommons.org/ licenses/by/4.0/deed.de.

\section{Literatur}

1. https://www.bka.de/DE/UnsereAufgaben/ Ermittlungsunterstuetzung/Erkennungsdienst/ erkennungsdienst.html?nn=30586\# doc19616bodyText5.Zugegriffen:02.07.2021

2. Cook R, Evett IW, Jackson G, Jones PJ, Lambert JA (1998) A hierarchy of propositions: deciding which level toaddress in casework. Sci Justice 38:231-239

3. Evett I, Jackson G, Lambert J (2000) More on the hierarchy of propositions: exploring the distinction between explanations and propositions. Sci Justice 40:3-10

4. Arnold J, Ottiker T (2019) Kriminalistisches Denken - systematisch, methodisch, logisch. Kriminalistik 1:50-54

5. Gill P (2014) Misleading DNA evidence: reasons for miscarriages of justice. Academic Press, London, S19-20 (174S.; hier:Kap. 1.7)

6. Schneider PM, Anslinger K, Eckert M, Fimmers R, Schneider H (2013) Erläuterungen zu den wissenschaftlichen Grundlagen biostatistischer Wahrscheinlichkeitsberechnungen im Rahmen von DNA-Spurengutachten. NStZ 12:693-697

7. Ulbrich W, Anslinger K, Bäßler G, Eckert M, Fimmers R, Hohoff C, Kraft M, Leuker C, Molsberger G, Pich U, Razbin S, Schneider H, Templin M, Wächter A, Weirich V, Zierdt H, Schneider PM (2016)

\section{Possibilities and limitations of forensic DNA analyses considering alternative propositions for the origin of biological traces. A statement of the German Stain Commission - a joint Commission of the Institutes of Legal Medicine and Forensic Science Institutes}

Over the last decades forensic DNA analysis has become an important tool in criminal investigations, aided by increasing sensitivity and a high level of technological standardization. Due to the continuing methodological improvements the successful genetic analysis of smaller and smaller latent DNA traces has been taken for granted. This leads to a shift in tasks for the forensic DNA expert regarding the evaluation of complex trace scenarios during a court trial. Rather than discussing an individual's DNA as the potential source of a DNA trace, questions put before the expert are now focussed on activities leading to potentially innocent depositions of biological material. The German Stain Commission recognizes the need to assess alternative scenarios of trace deposition. For the evaluation of forensic DNA findings within the context of further evidence in a given case scenario, we introduce the hierarchy of propositions, a wellestablished concept in the international literature of forensic science. Furthermore, the scientific basis of evaluating alternative DNA transfer scenarios and the possibilities and limitations of expressing an expert opinion are described.

\section{Keywords}

Hierarchy of propositions - DNA transfer - Probability - Expert testimony · Forensic genetics

Gemeinsame Empfehlungen der Projektgruppe „Biostatistische DNA-Berechnungen“ und der Spurenkommission zur biostatistischen Bewertung von DNA-analytischen Befunden. Rechtsmedizin 26:291-298

8. Gill P, Hicks T, Butler JM, Connolly E, Gusmão L, Kokshoorn B, Morling N, van Oorschot RAH, Parson W, Prinz M, Schneider PM, Sijen T, Taylor D (2018) DNA commission of the International society for forensic genetics: Assessing the value of forensic biological evidence-Guidelines highlighting the importance of propositions: Part I: evaluation of DNA profiling comparisons given (sub-) source propositions. Forensic Sci Int Genet 36:189-120

9. Gill P, Hicks T, Butler JM, Connolly E, Gusmão L, Kokshoorn B, Morling N, van Oorschot RAH, Parson W, Prinz M, Schneider PM, Sijen T, Taylor D (2020) DNA commission of the International society for forensic genetics: Assessing the value of forensic biological evidence-Guidelines highlighting the importance of propositions. Part II: Evaluation of biological traces considering activity level propositions. Forensic Sci Int Genet 44:102186

10. Taylor D, Kokshoorn B, Biedermann A (2018) Evaluation of forensic genetics findings given activity level propositions: a review. Forensic Sci Int Genet 36:34-49

11. Breathnach $M$, Williams $L$, McKenna $L$, Moore $E$ (2016) Probability of detection of DNA deposited by habitual wearer and/or the second individual who touched the garment. Forensic Sci Int Genet 20:53-60

12. Gill P (2016) Analysis and implications of the miscarriage of justice of Amanda Knoxand Raffaele Sollecito. Forensic Sci Int Genet 23:9-18

13. van Oorschot RAH, Szkuta B, Meakin GE, Kokshoorn B, Goray M (2019) DNA transfer in forensic science:a review. ForensicSci Int Genet38:140-166
14. Samie L, Hicks T, Castella V, Taroni F (2016) Stabbing simulations and DNA transfer. Forensic Sci Int Genet 22:73-80

15. Pfeifer CM, Wiegand P (2017) Persistence of touch DNA on burglary-related tools. Int J Legal Med 131:941-953

16. Daly DJ, Murphy C, McDermott SD (2012) The transfer of touch DNA from hands to glass, fabric and wood. Forensic Sci Int Genet 6:41-46

17. Pfeifer C, Miltner E, Wiegand P (2016) Analyse von Hautkontaktspuren in der forensischen Genetik unter besonderer Berücksichtigung ihrer Entstehung und Spurenentnahme. Rechtsmedizin 26:453-470

18. Goray M, Pirie E, van Oorschot RAH (2019) DNA transfer: DNA acquired by gloves during casework examinations. Forensic Sci Int Genet 38:167-174

19. Fonneløp AE, Egeland T, Gill P (2015) Secondary and subsequent DNA transfer during criminal investigation. Forensic Sci Int Genet 17:155-162

20. Pickrahn I, Kreindl G, Müller E, Dunkelmann B, Zahrer W, Cemper-Kiesslich J, Neuhuber F (2017) Contamination incidents in the pre-analytical phase of forensic DNA analysis in Austria-Statistics of 17 years. Forensic Sci Int Genet 31:12-18

21. Kanokwongnuwut $P$, Martin $B$, Kirkbride KP, Linacre A (2018) Shedding light on shedders. Forensic Sci Int Genet 36:20-25

22. Otten $L$, Banken $S$, Schürenkamp $M$, SchulzeJohann $\mathrm{K}$, Sibbing $\mathrm{U}$, Pfeiffer $\mathrm{H}$, Vennemann M (2019) Secondary DNA transfer by working gloves. Forensic Sci Int Genet 43:102126 